\section{The Assay of $\alpha$-Amylase}

By M. J. Clancy and C. E. O'Hara. (Department of Plant Chemistry and Biochemistry, The Agricultural Institute, Oak Park, Carlow, Irish Republic)

Many methods are described in the literature for estimating $\alpha$-amylase activity in wheat and wheaten flour, but most of them do not distinguish between the action patterns of wheat $\alpha$-and $\beta$-amylase, which are quite distinct. No one has described the action pattern resulting from the joint action of $\alpha$ and $\beta$-amylase on starch. Our studies have shown that $\alpha$-amylase from wheat cannot be reliably assayed by measurement of reducing power (product formation) irrespective of whether a soluble starch or amylopectin $\beta$-limit-dextrin is used as a substrate when $\beta$-amylase is present. In a study of the separate and joint actions of $\alpha$-and $\beta$-amylases on starch as measured by iodine staining (substrate disappearance) it was found that the presence of $\beta$-amylase markedly affected the rate of starch degradation.

We have investigated the selective assay of $\alpha$-amylase by $(a)$ the attempted specific inhibition of $\beta$-amylase (Clancy, O'Hara, Risseeuw \& Ryan, 1968) and (b) the use of a specific substrate for $\alpha$-amylase. In the first approach $(a)$ we have established that the inhibition with various thiol reagents is not enzyme-specific: both enzymes (amylases) are partially inhibited when an amount of inhibitor sufficient for the complete inhibition of $\beta$-amylase is used. We have also observed that the inhibition of $\beta$-amylase is not independent of starch concentration. The overall protein concentration in the assay mixture is also important since thiol-blocking reagents react with the thiol groups of this protein. In the second approach $(b)$ we have found pure amylopectin $\beta$-limit-dextrin to be a reasonably satisfactory substrate for $\alpha$ amylase assay when the amounts of $\beta$-amylase are not too high.

The arguments for these conclusions will be outlined.

We thank Miss M. T. Sweeney and Mr H. F. O'Shea for technical assistance.

Clancy, M. J., O'Hara, C. E., Risseeuw, P. S. \& Ryan, E. (1968). Biochem. J. 110, 7 P.

\section{Dissociation of $\beta$-Casein from Casein Micelles and Complexes}

By W. K. Downey, R. F. MURPhy and S. A. AHERne. (The Agricultural Institute, Moorepark, Fermoy, Co. Cork, Irish Republic)

The endothermic self-association of both $\alpha_{B^{-}}$and $\beta$-casein has been well documented (Hippel \& Waugh, 1955; Payens \& van Markwijk, 1963;
Payens \& Schmidt, 1965). In this study the effect of temperature on the dissociation of $\beta$-casein from the casein micelles of milk and from the soluble casein complexes of colloidal-phosphate-free milk (Pyne \& McGann, 1960) was investigated by highspeed centrifugation and by gel filtration at various temperatures $\left(0-25^{\circ}\right)$ on Sephadex G-200 and Sepharose 2B (Pharmacia, Uppsala, Sweden) columns equilibrated with a buffer similar in composition to milk ultrafiltrate.

The removal of most (approx. 65\%) of the $\beta$-casein from casein micelles of milk by gel filtration at $5^{\circ}$ on Sepharose 2B columns was not attended by a marked decrease in the size of the casein micelles, nor was there any indication of micellar disintegration. Thus, although $\beta$-casein may constitute the structural lattice of the subunits of casein micelles (Rose, 1969), less than $40 \%$ of the total $\beta$-casein appears to be required for this function. Further, the elution from Sepharose 2B columns at $25^{\circ}$ of all the $\beta$-casein of colloidal-phosphate-free milk, together with the $\alpha_{\mathrm{s}^{-}}$and $\kappa$-caseins, apparently as complexes of molecular size approx. $2 \times 10^{6}$ (Murphy, Downey \& Kearney, 1969), indicates that colloidal phosphate is not essential for the association of $\beta$-casein with the structural subunits of casein micelles.

The decrease in free $\beta$-casein obtained by gel filtration on Sepharose $2 B$, from $65 \%$ to approx. $20 \%$, when the fractionation temperature is decreased from $5^{\circ}$ to $0^{\circ}$, appears to be due to a decreased dissociation of $\beta$-casein from casein micelles or complexes, rather than to a polymerization of free $\beta$-casein.

The large amount of non-micellar $\beta$-casein (approx. 65\% of the total) obtained on gel filtration at $5^{\circ}$ on Sepharose 2B, relative to that (approx. $10 \%$ of total) obtained by comparable fractionations on Sephadex G-200, or in high-speed supernatants $\left(34000 \mathrm{~g}\right.$ at $5^{\circ}$ for $2 \mathrm{hr}$.) is difficult to explain. However, it appears that, on cooling milk to $5^{\circ}$, approx. $10 \%$ of the $\beta$-casein dissociates from the micelles as aggregates (mol.wt. approx. 200000) that are in equilibrium with the micellar $\beta$-casein. During gel filtration on Sepharose $2 B$, the $\beta$-casein enters the gel pores and is rapidly separated from the micellar casein, which is excluded from the gel. Additional $\beta$-casein is consequently released from the micelles to re-establish equilibrium. In contrast, on Sephadex G-200, the liberated soluble $\beta$-casein aggregates are not completely separated from the casein micelles, and the equilibrium is not sufficiently disturbed to result in appreciable dissociation of $\beta$-casein from the micelles.

Hippel, P. H. von \& Waugh, D. F. (1955). J. Amer. chem. Soc. 77, 4311.

Murphy. R. F.. Downey, W. K. \& Kearney, R. D. (1969). Biochem. J. 115, 22 P. 